\title{
Vaccination of Algerian Local Rabbits with Precocious Strains of Eimeria magna and Eimeria media
}

\author{
Mohamed Sadek Bachene ${ }^{1,2 *}$, Soraya Temim ${ }^{1}$, Hassina Ainbaziz ${ }^{1}$ and Asma Bachene ${ }^{2}$ \\ ${ }^{I}$ Research of Animal Health and Production Laboratory, Higher National Veterinary School, BP 161, Rue Issad Abbes, OuedSmar, Algiers, Algeria \\ ${ }^{2}$ Department of Nature and Life Sciences, DrYahiaFarès University, Médéa, Algeria \\ *Corresponding author's Email: bmsouzra@yahoo.fr; (D)RCiD: 0000-0001-7192-8437
}

\begin{abstract}
The present study was conducted to assess the safety and the efficacy of a vaccine containing the Algerian precocious strains of Eimeria magna and Eimeria media used separately or together against rabbit coccidiosis. The samples consisted of 56 young rabbits reared in specific pathogen-free conditions. Following the challenge inoculation, statistically significant decreases in oocyst excretion were noticed in the vaccinated rabbits with the precocious strain of Eimeria magna, Eimeria media, and both species leading toa good immune response acquired by the vaccination associated with a good growth rate. Moreover, there was a statistically significant increase in oocyst output following the challenge in all challenged groups. Unlike the vaccinated groups, the challenged groups showed poor weight gains. More than $50 \%$ of the young rabbits from all the challenged groups presented diarrhea. Consequently, these precocious strains constitute good candidates for mono or polyvalent anticoccidial vaccines in the future.
\end{abstract}

Keywords: Precocious strain, Rabbits, Vaccination, Wild strain.

\section{INTRODUCTION}

Coccidiosis is recognized as one of the major handicaps in rabbit breeding (Cowie-Whitney, 1977). It causes considerable economic losses due to the decrease in weight gain, diarrhea, and even death (Drouet-Viard et al., 1997a; Drouet-Viard et al., 1997b). All domesticated rabbit breeds can be infected by coccidia, especially the younger animals aged one to four months (Drouet-Viard et al., 1997a; González-Redondo et al., 2008; Bachene et al., 2018). For a long time, the control of rabbit coccidiosis was based on continuous administration of anticoccidial drugs in feed or drinking water. The use of anticoccidial drugs resulted in drug-resistant problems in rabbit farming (Coudert et al., 1988; Peeters et al., 1988). Inoculation with live attenuated Eimeria parasites could provide sufficient protection against the challenges with the corresponding wild strains (Akpo et al., 2012; Bachene et al., 2018) and provides a practical way to develop the attenuated vaccine against rabbit coccidiosis. In Algeria, some studies have reported the epidemiological status of coccidiosisinrabbits,showing that E. magna and E. media are the predominant species of Eimeria (Henneb and Aissi, 2013; Maziz-bettahar et al., 2018). Therefore, in the present study both precocious strains of E.magna and E. media were tested separately and together to evaluate and compare the parental strains in terms of their safety and efficacy as vaccine strains against rabbit coccidiosis.

\section{MATERIAL AND METHODS}

\section{Ethical approval} Algeria.

The current study was approved by the scientific council of the higher National Veterinary School of Algiers,

\section{Parasites}

Wild strains of Eimeria magna and Eimeria media

The wild strains of Eimeriaspp. were isolated in Algeria in 2014 from local rabbits and inoculated to coccidia-free rabbits, then purified and preserved in $2.5 \%$ potassium dichromate solution at $4^{\circ} \mathrm{C}$.

\section{Precocious strain of Eimeria magna}

Precocious strain of E. magnaobtained from previous study (Bachene et al., 2018) in Algeria in 2016, was used in the current study. Briefly, the precocious strain of E. magna was obtained from the corresponding Algerian wild strain by the selection of the early oocyst excretion after nine passages in coccidia-free rabbits and preserved in $2.5 \%$ potassium dichromate solution at $4^{\circ} \mathrm{C}$. 


\section{Precocious strain of Eimeria media}

A precocious strain of E.media was obtained in Algeria in 2016 from the corresponding Algerian wild strain by the selection of the early oocyst excretion after 13 passages in coccidia-free rabbits according to the method described by Licois et al. (1990). Table 1 summarizes the selection process of precocious strain of E.media. This strain was preserved in $2.5 \%$ potassium dichromate solution at $4^{\circ} \mathrm{C}$.

Table 1.Selection of the precocious strain of Eimeria media.

\begin{tabular}{|c|c|c|c|}
\hline Inoculated strain & Inoculation dose & $\begin{array}{c}\text { Time interval between inoculation and } \\
\text { collection of the first oocysts from fecal } \\
\text { contents (hours) }\end{array}$ & Obtained strain \\
\hline WS.Emed2014 & $10^{4}$ oocysts & 108 & S1 \\
\hline S1 & $2 \times 10^{4}$ oocysts & 102 & $\mathrm{~S} 2$ \\
\hline $\mathrm{S} 2$ & $3 \times 10^{4}$ oocysts & 96 & S3 \\
\hline S3 & $5 \times 10^{4}$ oocysts & 92 & S4 \\
\hline S4 & $5 \times 10^{4}$ oocysts & 90 & S5 \\
\hline S5 & $5 \times 10^{4}$ oocysts & $90^{\mathrm{a}}$ & S6 \\
\hline S6 & $5 \times 10^{4}$ oocysts & 90 & S7 \\
\hline S7 & $5 \times 10^{4}$ oocysts & 90 & S8 \\
\hline S8 & $5 \times 10^{4}$ oocysts & 90 & S9 \\
\hline S9 & $5 \times 10^{4}$ oocysts & 88 & $\mathrm{~S} 10$ \\
\hline $\mathrm{S} 10$ & $5 \times 10^{4}$ oocysts & 84 & S11 \\
\hline S11 & $10^{5}$ oocysts & 78 & $\mathrm{~S} 12$ \\
\hline $\mathrm{S} 12$ & $10^{5}$ oocysts & 72 & PS.Emed 2016 \\
\hline
\end{tabular}

WS.Emed2014: Wild strain of Eimeria media obtained in 2014. PS.Emed 2016: Precocious strain of Eimeria media obtained in 2016.

\section{Experimental design}

The samples consisted of 56 young rabbits reared in specific pathogen-free conditionsas described by Coudert et al. (1988). All the young rabbits were fed ad libitum with a commercial pelleted food free from anticoccidial drugs. They were weaned at 25 days old and divided into 7 groups ( 8 rabbits per group). The NNC group was associatedwithnonvaccinated non-inoculated control group, the NCma group referred to non-vaccinated, challenged with the wild strain of E. magna, the NCmesignifiednon-vaccinated, challenged with the wild strain of E media. Moreover, NCmame group dealt withnon-vaccinated, challenged with the wild strains of E. magna and E. media, the VCma group addressed vaccinated with the precocious strain of E. magna, challenged with the wild strain of $E$ magna, the VCme group includedvaccinated cases with the precocious strain of $E$. media, challenged with the wild strain of $E$ media, and finally VCmame group entailedvaccinatedcases with the precocious strains of E. media and E. magna, challenged with both corresponding wild strains.

At 27 days of age, each rabbit in the vaccinated groups received the corresponding Eimeria spp. orally at a dose of $2.5 \times 10^{3}$ oocysts/ $0.2 \mathrm{ml}$ of distilled water. The vaccinated group with both Eimeriaspp. received half of the above dose of each.At 40 days of age, each rabbit in challenged groups was orally inoculated with corresponding Eimeria spp. at a dose of $5 \times 10^{4}$ oocysts $/ 0.2 \mathrm{ml}$ of distilled water. The inoculated group with both Eimeriaspp. received half of the above dose of each.

\section{Fecal sampling and parasitological analysis}

Feces were daily collected from each group from day 2 post-vaccination to day 21 post-challenge. Oocysts counting was performed as described by Coudert et al. (1995).

\section{Rabbit monitoring}

The animals were weighed once every 3 days for 32 days. Animals were examined to detect diarrhea or any other abnormalities.

\section{Statistical analysis}

Statistical analysis was performed by one-way ANOVA post hoc multiple comparisons using the SPSS software (version17). The oocyst excretion and means of average weights per time across the seven studied groups were compared and the difference between groups was considered statistically significant when p-values were less than 0.05 .

\section{RESULTS}

\section{Oocysts output after vaccination and challenge inoculation}

In the vaccinated group with the precocious strain of E. magna, total excretion throughout the experiment period was $22.4 \times 10^{6}$ oocysts per rabbit. After the challenge inoculation (13 days post-vaccination) the oocyst excretion decreased significantly with a percentage of $98.4 \%$, compared to the unvaccinated group.In the vaccinated group with 
the precocious strain of E. media, total excretion throughout the experiment period was $36.8 \times 10^{6}$ oocysts. After the challenge inoculation (13 days post-vaccination) the oocyst excretion decreased significantly with a percentage of $98.9 \%$, compared to the unvaccinated group.Vaccinated rabbits with the mixture of both precocious strains of E. magna and $E$. media multiplied these parasites with a total excretion of $28.4 \times 10^{6}$ oocysts. After the challenge inoculation (13 days post-vaccination) the oocyst excretion decreased significantly with a percentage of $99.4 \%$, compared to the unvaccinated group. There was no significant difference between the vaccinated groups in terms of oocysts output reduction (Table 2 ).

\section{Average weight gains per time}

The control group showed regular growth throughout the experiment. The vaccinated groups (VCma, VCme, VCmame) indicated good growth during the experiment with acceptable weight gains (Figure 1) compared to the control group $(\mathrm{p}<0.05)$.

\section{Mortality and clinical symptoms}

No mortality occurred in any group throughout the experiment. No case of diarrhea was noticed in the vaccinatedchallenged groups (VCma, VCme, VCmame) as well as the control one (NNC). However, some cases of diarrhea occurred in all challenged non-vaccinated groups. For instance, three rabbits from the NCma group showed diarrhea 7-10 days after the challenge and two others from the NCme group suffered from diarrhea 6-9 days after the challenge. In NCmame group, diarrhea was noticed in 6 rabbits during a period of 6-10 days post-inoculation.

Table 2. Total oocysts output per rabbit after vaccination and challenge infection with Eimeria species.

\begin{tabular}{l|c|c|c}
\hline \multirow{2}{*}{ Groups } & \multicolumn{2}{|c|}{ Oocyst output } & $\begin{array}{c}\text { Reduced percentage of oocyst excretion in vaccinated } \\
\text { groups compared with unvaccinated groups }\end{array}$ \\
\hline NNC & After vaccination & After challenge & - \\
\hline NCma & - & - & - \\
NCme & - & $341.4 \times 10^{6}$ & - \\
\hline NCmame & - & $395.5 \times 10^{6}$ & - \\
\hline VCma & - & $898.4 \times 10^{6}$ & $98.4 \%$ \\
\hline VCme & $22.4 \times 10^{6}$ & $5.4 \times 10^{6}$ & $98.9 \%$ \\
\hline VCmame & $36.8 \times 10^{6}$ & $4.4 \times 10^{6}$ & $99.4 \%$ \\
\hline
\end{tabular}

NNC: Non-vaccinated,non-challenged control group; NCma: Non-vaccinated, challenged with the wild strain of $E$ magna; NCme: Non-vaccinated, challenged with the wild strain of $E$ media; NCmame: Non-vaccinated, challenged with the wild strains of $E$ magna and $E$ media; VCma: Vaccinated with the precocious strain of $E$ magna- challenged with the wild strain of $E$ magna; VCme: Vaccinated with the precocious strain of $E$ media, challenged with the wild strain of $E$ media; VCmame: Vaccinated with the precocious strains of $E$ media and $E$ magna, challenged with the corresponding wild strains.

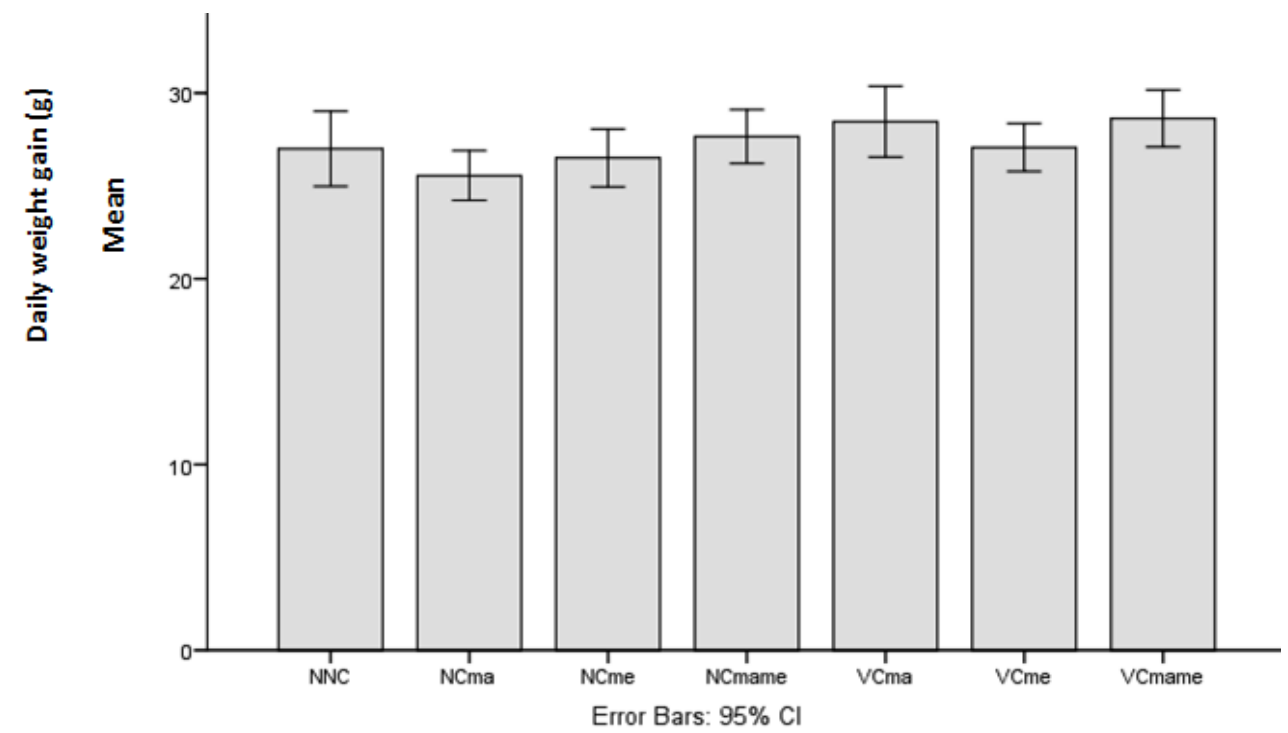

Figure 1. Average daily weight gains post-vaccination in the seven studied groups. NNC: Non-vaccinated non challenged control group. NCma: Non-vaccinated - challenged with the wild strain of $E$ magna. NCme: Non-vaccinated - challenged with the wild strain of $E$ media. NCmame: Non-vaccinated - challenged with the wild strains of $E$ magna and $E$ media. VCma: Vaccinated with the precocious strain of $E$ magna- challenged with the wild strain of $E$ magna. VCme: Vaccinated with the precocious strain of $E$ media- challenged with the wild strain of $E$ media. VCmame: Vaccinated with the precocious strains of $E$ media and $E$ magnachallenged with the corresponding wild strains. The challenged groups (NCma, NCme, NCmame) showed low weight gains, compared to vaccinated and control groups (Figure 2). 


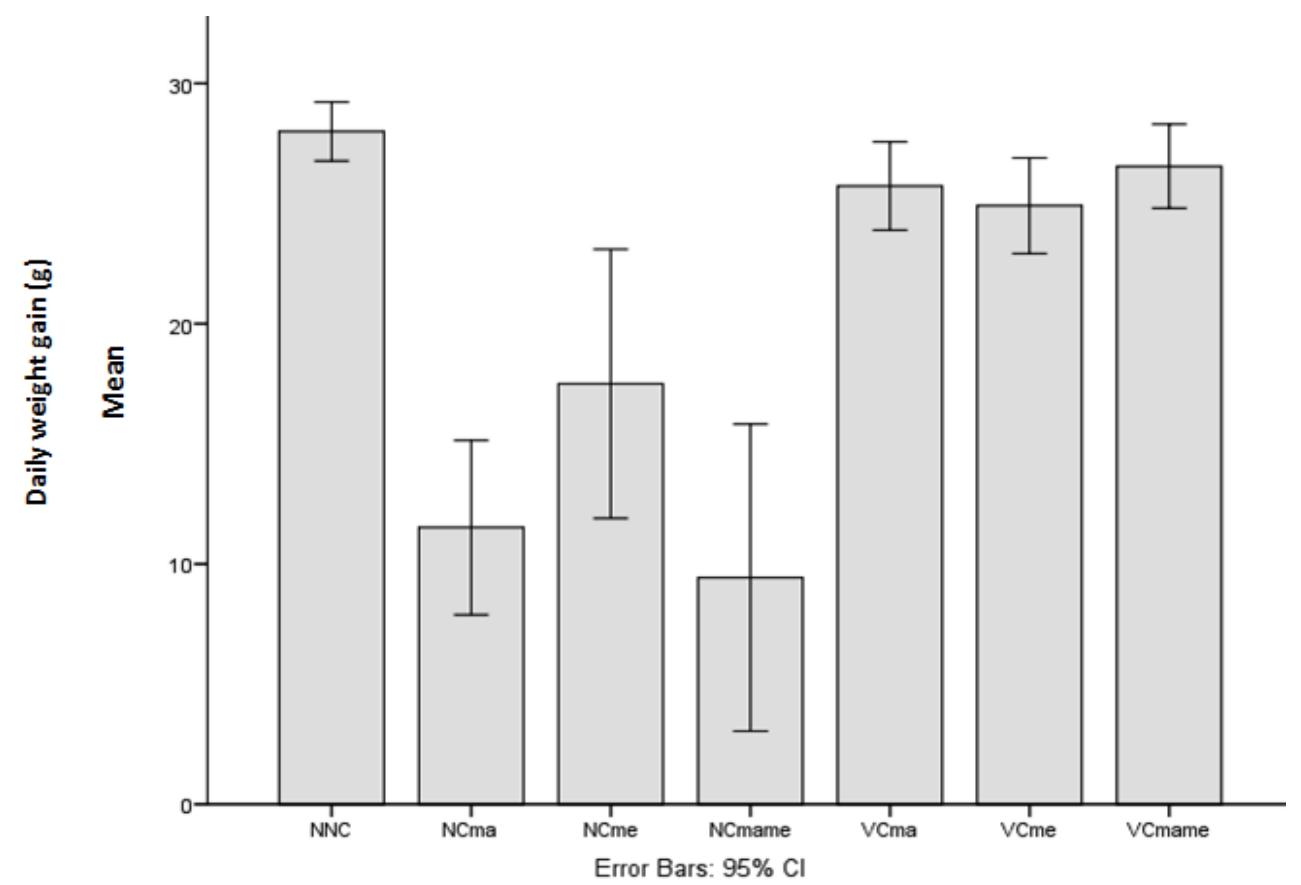

Figure 2. Average daily weight gains post-challenge infection in the seven studied groups.NNC: Non-vaccinated non challenged control group. NCma: Non-vaccinated - challenged with the wild strain of E magna. NCme: Non-vaccinated - challenged with the wild strain of E media. NCmame: Non vaccinated - challenged with the wild strains of $E$ magna and $E$ media. VCma: vaccinated with the precocious strain of $E$ magna- challenged with the wild strain of $E$ magna. VCme: vaccinated with the precocious strain of $E$ media- challenged with the wild strain of $E$ media. VCmame: vaccinated with the precocious strains of E media and $E$ magna-challenged with the corresponding wild strains.

\section{DISCUSSION}

E. magna and E. media are considered as mildly pathogenic (Licois et al., 1995), and are also the most predominantEimeria species in rabbit breeding (Coudert et al., 1988; Licois et al., 1995; HennebandAissi, 2013; MazizBettahar et al., 2018; Bachene et al., 2019). The mentioned strains were used in the current study separately or together as a live attenuated vaccine for rabbits. Following vaccination, the precocious strains of E. magna and E. media reproduced in young rabbits (VCma, VCme, VCmame) without expressing the disease, testifying to the viability of these strains and the attenuation of their pathogenicity. Indeed, vaccination could protect rabbits against challenge infection. In the present experiment, a dose of $2.5 \times 10^{3}$ oocysts of precocious strains of E. magna, E. media, or both strains led to the partial protection of the investigated samples. In fact, the results indicated a decrease in oocyst output of about $98.4 \%$, 98.9\%, and 99.4\% in VCma, VCme, Vcmamegroups, respectively compared with challenged non-vaccinated groups. However, the non-vaccinated, challenged groups with the wild strains of E. magna, E. media separately or together displayed diarrhea. There was no statistically significant difference between the vaccinated groups with a single species or with the two species together, this can encourage the use of polyvalent vaccines against rabbit coccidiosis since the natural infections with a single Eimeriaspecies are rare as reported previously (Jing et al., 2012; Abdel-Baki and AlQuraishy, 2013). The result demonstrated the attenuation of E. magna and E. media precocious strain's pathogenicity is globally in agreement with the results of Licois et al. (1995), Pakandl et al. (1996), Drouet-Viard et al. (1997a, 1997b, 1997c), and Bacheneet al. (2018).

\section{CONCLUSION}

The Algerian precocious strains of Eimeria magna and E. media were less pathogenic, compared to the wild strains. On the other hand, their effectiveness has been verified by the challenge inoculation using Algerian wild strains of $E$. magna and E. media leading to a satisfactory result in terms of acquired protection. Consequently, the findings indicated the absence of mortality and morbidity as well as a decrease in oocyst output after the challenge inoculation. Vaccination seems to be efficient when performed when rabbits are as old as 27 days giving time to young rabbits to develop sufficient immunity at weaning. Given these results, these precocious strains of E. magna and E. media appear to be suitable candidates for use as live attenuated single or polyvalent vaccines in rabbit breeding. 


\section{DECLARATIONS}

\section{Competing interests}

The authors declare that they have no conflict of interests.

\section{Authors' contributions}

MSB proposed and conducted the study. MSB and AB drafted and revised the manuscript. ST and HA supervised the work. MSB and AB analyzed the data. All authors read and approved the final manuscript.

\section{REFERENCES}

Abdel-Baki AAS, and Al-Quraishy S (2013). Prevalence of coccidia (Eimeriaspp.) infection in domestic rabbits, Oryctolaguscuniculus, in Riyadh, Saudi Arabia. Pakistan Journal of Zoology, 45(5): 1329-1333. Available at: http://zsp.com.pk/pdf45/1329-1333\%20_20_\%20PJZ-1386-13\%2019-9-13\%20Revised\%20MS\%20_1_.pdf

Akpo Y, Kpodékon MT, Djago Y, Licois D, and Youssao IA (2012). Vaccination of rabbits against coccidiosis using precocious lines of Eimeriamagna and Eimeria media in Benin. Veterinary Parasitology 184: 73-76. DOI: https://doi.org/10.1016/j.vetpar.2011.08.012

Bachene MS, Temim S, Ainbaziz H, Bachene A and Suo X (2018). A vaccination trial with a precocious line of Eimeria magna in Algerian local rabbits Oryctolagus cuniculus. Veterinary Parasitology, 261: 73-76. DOI: https://doi.org/10.1016/j.vetpar.2018.08.013

Coudert P, Licois D, and Drouet-Viard F (1995). Eimeria species and strains of rabbits. In: Eckert, J., Braun, R., Shirley, M.W., Coudert, P, Sc (Eds.), Biotechnology Guidelineson Techniques in coccidiosis Research. European commission, Luxembourg, pp. 52-73. Availableat: http://ndl.ethernet.edu.et/handle/123456789/47174

Coudert P, Licois D, and Besnard J (1988). Establishment of a specified pathogen free breeding colony (SPF) without hysterectomy and hand-rearing procedures. Proceedings of the 4th Congress of the World Rabbit Science Association, pp. 137-148. Available at: http://world-rabbit-science.com/WRSA-Proceedings/Congress-1988-Budapest/communications-pdf/G08-COUDERT.pdf

Cowie-Whitney J (1977). Diseases of the commercial rabbit.Veterinary Record, 101: $299-303$. DOI: https://doi.org10.1136/vr.101.15.299

Drouet-Viard F, Coudert P, Licois D, and Boivin M (1997a). Vaccination against Eimeria magnacoccidiosis using spray dispersion of precocious line oocysts in the nest box. Veterinary Parasitology 70: 61-66. DOI: https://www.doi.org/10.1016/S0304$\underline{4017(96) 01134-X}$

Drouet-viard F, Coudert P, Licois D, and Boivin M (1997b). Vaccination trial against Eimeria magnacoccidiosis using a precocious line. World RabbitScience, 5(2): 51-54. DOI: https://www.doi.org/10.1016/S0304-4017(96)01133-8

Drouet-viard F, Coudert P, Licois D, and BoivinM(1997c).Acquired protection of therabbit (Oryctolagus cuniculus) against coccidiosis using a precocious line of Eimeria magna: effect of vaccine dose and age at vaccination.Veterinary Parasitology, 69: 197-201. DOI: https://www.doi.org/10.1016/S0304-4017(96)01133-8

González-Redondo P, Finzi A, Negretti P, and Micci M (2008). Incidence of coccidiosis in different rabbit keeping systems.ArquivoBrasileiro de MedicinaVeterinária e Zootecnia, 60(5): 1267-1270. DOI: https://www.doi.org/10.1590/S0102$\underline{09352008000500034}$

Henneb M, and Aissi M (2013). Etude cinétique de l'excrétion oocystale chez la lapine et sa descendance et identification des différentes espèces de coccidies. 15 th day of research about rabbits, November 19 th -20 th France, pp. 221-224. Available at: http://www.cuniculture.info/Docs/Magazine/Magazine2013/fichiers-pdf-JRC/P02-Henneb.pdf

Jing F, Yin GW, Liu XY, Suo X, and Qin YH (2012). Large-scale survey of the prevalence of Eimeria infections in domestic rabbits in China. Parasitology Research, 110(4): 1495-1500. DOI: https://doi.org/10.1007/s00436-011-2653-4

Licois D, Coudert P, Boivin M, Drouet-Viard F, and Provot F (1990). Selection and characterization of a precocious line of Eimeriaintestinalis, an intestinal rabbit coccidium. Parasitology Research, 76: 192-198. DOI: https://www.doi.org/10.1007/BF00930814

Licois D, Coudert P, Drouet-Viard F, and Boivin M (1995). Eimeria magna: pathogenicity, immunogenicity and selection of a precocious line. Veterinary Parasitology, 60: 27-35. DOI: https://www.doi.org/10.1016/0304-4017(94)00768-8

Maziz-Bettahar S, Aissi M, Ainbaziz H, Bachene MS, Zenia S, and Ghisani F (2018). Prevalence of coccidian infection in rabbit farms in North Algeria. Veterinary World, 11(11): 1569-1573. DOI: https://www.doi.org/10.14202/vet world.2018.1569-1573

Pakandl M, Eid Ahmed N, Licois D, and Coudert P (1996). Eimeria magan Pérard: Study of the endogenous development of parental and precocious strains. Veterinary Parasitology, 65: 213-222. DOI: https://www.doi.org/10.1016/s0304-4017(96)00975-2

Peeters JE,Geeroms R, and Halen P (1988). Evolution of coccidial infection in commercial and domestic rabbits between 1982 and 1986. Veterinary Parasitology, 29: 327-331. DOI: https://www.doi.org/10.1016/0304-4017(88)90149-5 